\title{
Complete heart block in patients with peroneal muscular atrophy
}

\author{
B. A. J. PONDER \\ M.B., M.R.C.P.
}

\author{
K. ChatterJeE* \\ M.B., M.R.C.P., M.R.C.P.E.
}

\author{
G. C. Sutton \\ M.B., M.R.C.P.
}

The Cardiac Department, Brompton Hospital, London, S.W.3

\section{Summary}

Two patients with peroneal muscular atrophy who also had complete heart block are reported.

The pathogenesis of heart block in one of these patients was investigated by left ventricular volume analysis which showed a normal ejection fraction, indicating intact left ventricular function. This patient in addition had a normal coronary arteriogram.

These findings suggest that heart block in patients with peroneal muscular atrophy may be due to primary conduction tissue disease rather than cardiomyopathy.

\section{Introduction}

Atrioventricular (A-V) block is an uncommon finding in patients with peroneal muscular atrophy (PMA). Littler (1970) reported a family, some members of which had features of peroneal muscular atrophy and some of which had evidence of conducting tissue defects. Only one patient had both complete heart block and peroneal muscular atrophy. No other similar patients have been described.

This study reports two further patients who had both clinical features of PMA and complete heart block. In an attempt to define the mechanism of heart block, cardiac catheterization and left ventricular function studies have been performed in one of these patients.

\section{Methods of investigation}

Routine clinical examination including chest Xrays and electrocardiograms, was performed in both patients. In particular, a survey was made in each family for heart disease or heart block, and for neurological abnormalities. One patient agreed to further investigation by cardiac catheterization. Routine right and left heart catheterization was performed, using conventional techniques, pressure

Requests for reprints: Cardiac Department, Brompton Hospital, London, S.W.3.

* Present address: Department of Cardiology, CedarsSinai Medical Centre, Los Angeles, California, U.S.A. measurements being referred to the mid-chest level. Left ventricular volumes were calculated by singleplane (antero-posterior projection) cine-angiography, according to the method previously reported from this laboratory (Chatterjee et al., 1971). Ejection fraction was calculated from angiographically estimated end-diastolic (EDV) and end-systolic (ESV) volumes, according to the formula:

$$
\mathrm{EF}=\frac{\mathrm{EDV}-\mathrm{ESV}}{\mathrm{EDV}}
$$

and compared to the EF similarly obtained in normal controls. Selective coronary arteriography was performed according to the technique of Sones \& Shirey (1962).

The clinical diagnosis of peroneal muscular atrophy was confirmed by a neurologist in both patients.

\section{Case reports}

Patient No. 1

J. A. 49 years old, male. This patient had been noted to have clinical cardiac enlargement in early adult life, confirmed by chest X-ray. He had noticed a slow pulse accelerating on exercise for many years. At the age of 39, he had a number of fainting attacks, but these did not persist and were not investigated. He was first seen in this hospital in 1965 after a routine ECG had shown complete heart block. He remained asymptomatic until June 1970, when he had a right hemiplegia and homonymous field defect, thought to be due to a cerebral embolism. He had been anticoagulated and the hemiplegia had resolved. He was aware that his legs and arms were unusually thin and knew that his father, who was dead, had similar features. The remainder of the family were all clinically normal, but the ECG of one of his four children showed a partial right bundle branch block.

Abnormal neurological findings included severe wasting of the small muscles of both hands and both 
calves and peronei, with mild pes cavus (Fig. 1). The knee jerks were brisk but the other tendon reflexes were absent and the plantar responses were equivocal. Abnormal cardiovascular findings were a heart rate of $40 / \mathrm{min}$ and an ejection systolic murmur throughout the precordium, with physiological splitting of the second heart sound.

Chest X-ray showed cardiac enlargement with normal lung fields. ECG (Fig. 2) showed a ventricular rate of $40 / \mathrm{min}$ without $P$ waves. The $Q R S$ duration was $0.08 \mathrm{sec}$ and the QRS axis $-60^{\circ}$.

Routine haematological, biochemical and serological investigations were all negative.

Cardiac catheterization showed a normal mean right atrial (RA) pressure without ' $a$ ' waves, slight elevation of right ventricular (RV) systolic pressure and a wide pulmonary artery (PA) pressure (RV 45/4-10 mmHg, PA 40/15 mmHg); left ventricular (LV) end-diastolic pressure was slightly elevated (LV 170/12-15 mmHg). Intracardiac ECG confirmed atrial fibrillation and complete A-V block. Selective right and left coronary arteriography were normal. Results of left ventricular volume analysis are summarized in the table.

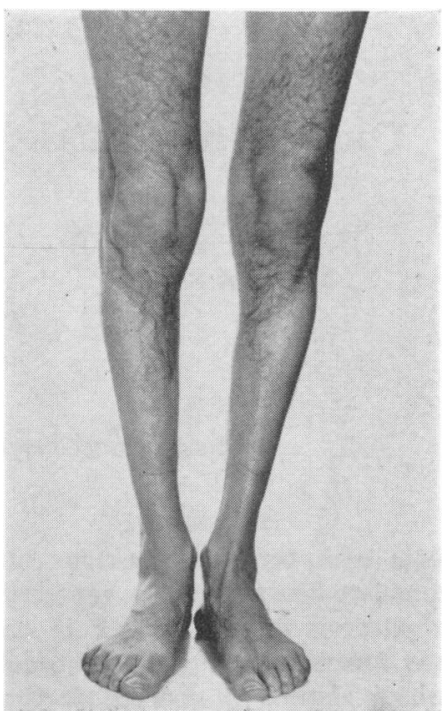

FIG. 1. Wasting of the peronei with mild bilateral pes cavus (Patient No. 1).

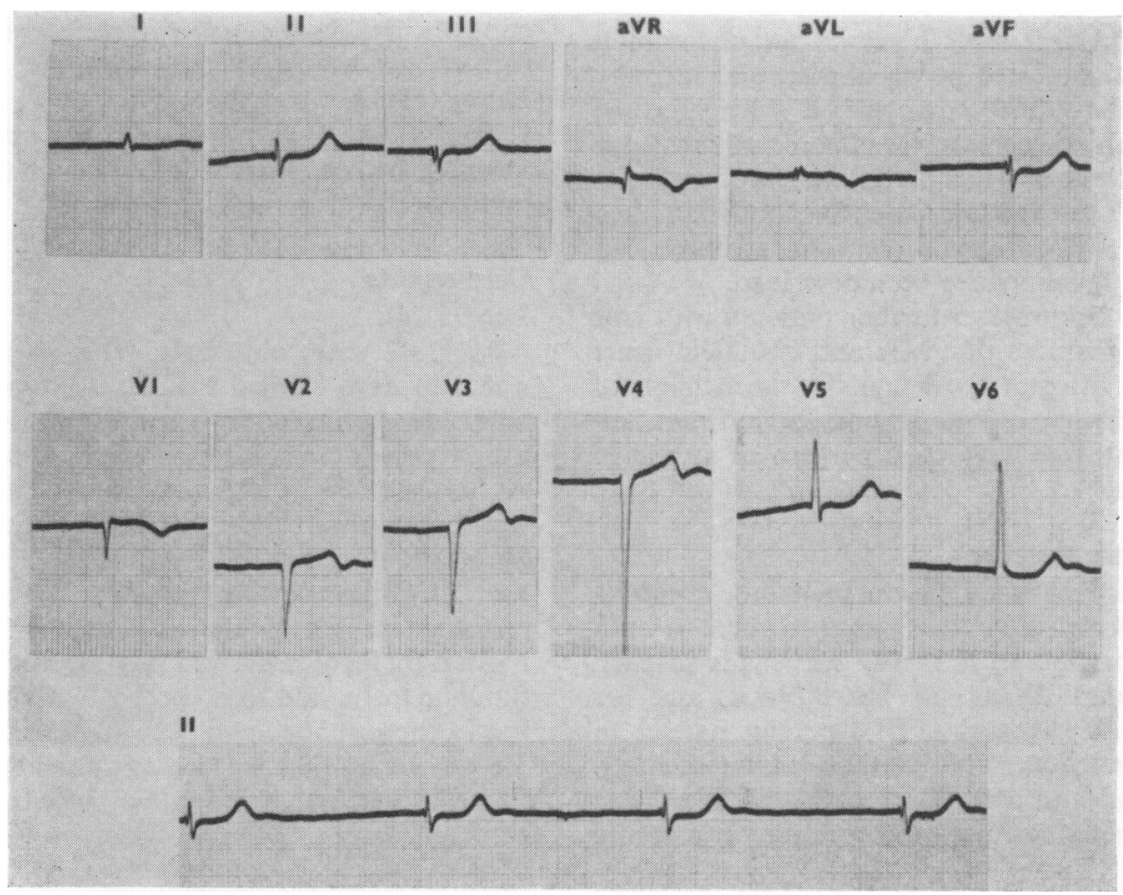

FIG. 2. Conventional electrocardiogram (Patient No. 1). Regular ventricular activity (rate $40 / \mathrm{min}$ ) without any atrial activity. (Intracardiac ECG showed atrial fibrillation with complete heart block.) 
TABLE 1. Left ventricular volume data in a patient with peroneal muscular atrophy

\begin{tabular}{lcc}
\hline & $\begin{array}{c}\text { Normal } \\
\text { range* }\end{array}$ & Patient 1 \\
\hline $\operatorname{EDV}\left(\mathrm{ml} / \mathrm{m}^{2}\right)$ & $54-108$ & 255 \\
LVSV $\left(\mathrm{ml} / \mathrm{m}^{2}\right)$ & $37-72$ & 196 \\
EF & $0.66-0.75$ & 0.77 \\
Heart rate $/ \mathrm{min}$ & $53-87$ & 38 \\
\hline
\end{tabular}

* Reported in a previous communication (Chatterjee et al., 1971).

EDV, end-diastolic volume; LVSV, left ventricular stroke volume; EF, ejection fraction.

\section{Patient No. 2}

G. B. age 57, male. This patient was referred for investigation of slow heart rate, discovered during routine clinical examination. There was no family

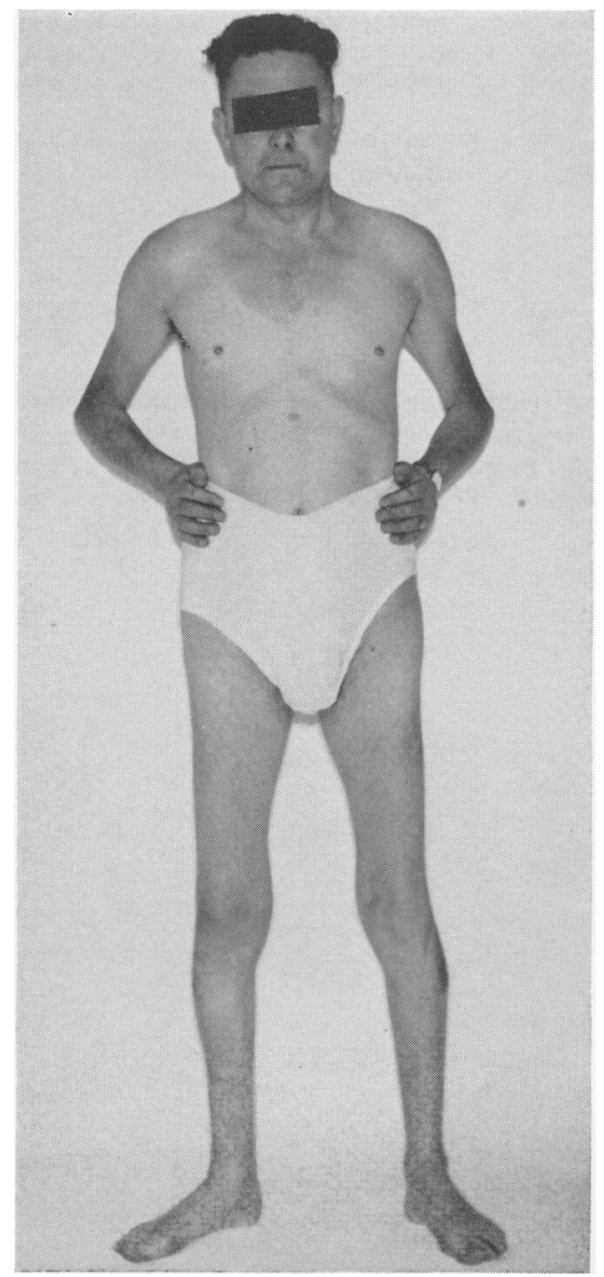

FIG. 3. 'Inverted bottle' appearance of upper and lower limbs in Patient No. 3. history of heart disease or any familial incidence of neurological disturbance suggesting peroneal muscular atrophy.

Examination of the nervous system showed bilateral symmetrical wasting of the peroneal muscles, with an 'inverted bottle' appearance (Fig. 3). There was slight wasting of the small muscles of the hands and forearms with diminished knee jerks, absent ankle jerks and equivocal plantar responses. He had a steppage gait, with slight bilateral pes cavus.

His heart rate was $40 / \mathrm{min}$. There were no murmurs and wide splitting of the second heart sound, varyıng normally with respiration, but abnormally wide on expiration.

Chest X-ray showed generalized cardiac enlargement, without any other abnormality. ECG showed atrial flutter, with complete $\mathrm{A}-\mathrm{V}$ block with an idioventricular rate of $42 / \mathrm{min}$; QRS duration was $0 \cdot 16 \mathrm{sec}$ and $\mathrm{QRS}$ axis $-30^{\circ}$. There was right bundle branch block in the precordial leads. Cardiac catheterization was not performed.

Routine haematological, serological and biochemical investigations were all negative.

\section{Discussion}

Chronic heart block may be due to either isolated defects of conducting tissue (e.g. congenital heart block or idiopathic bilateral bundle branch fibrosis (Zoob \& Smith, 1963; Davies \& Harris, 1969)) or involvement of conducting tissue secondary to generalized disease of the myocardium (Davies \& Harris, 1969).

An association between peroneal muscular atrophy and heart block has been reported (Littler, 1970) and our observations in these two patients reinforce this association.

The mechanism of heart block in peroneal muscular atrophy is not clear. As cardiomyopathy has been reported in patients with the Roussy-Levy syndrome, thought to be a variant of peroneal muscular atrophy (Lascells, Baker \& Thomas, 1970), it is possible that primary myocardial disease, if it also occurs in patients with peroneal muscular atrophy, may secondarily involve the conducting tissue causing heart block. On the other hand, heart block may be due to a primary disease of the conducting tissue, perhaps genetically determined as suggested by Littler (1970).

Unfortunately, in the majority of patients with chronic heart block, the history, physical signs and electrocardiogram are of little value in predicting the presence or absence of significant myocardial disease (Harris et al., 1969; Chatterjee et al., 1970). Ejection fraction (the ratio of left ventricular stroke volume to left ventricular end-diastolic volume) derived from angiographic left ventricular volume analysis provides a reliable index of left ventricular 
function and can be used to differentiate patients with cardiomyopathy from those with intact left ventricular function (Bartle, Sanmarco \& Dammann; 1965; Miller, Kirklin \& Swan, 1965; Dodge \& Baxley, 1969). Cine-angiographic volume analysis in one patient in this study showed a greatly increased left ventricular end-diastolic volume by comparison with normals (Chatterjee et al., 1971). Such an increase in end-diastolic volume is presumably due to long-standing slow heart rate. Despite the increased end-diastolic volume, left ventricular stroke volume was also proportionately increased, so that the ejection fraction remained normal, indicating intact left ventricular function and excluding significant myocardial disease. Thus heart block in this patient was due to primary disturbance of conducting tissue and not cardiomyopathy.

The mechanism of selective involvement of the conducting tissue in these patients remains unresolved. However, normal coronary arteriography made an ischaemic aetiology unlikely in J. A. The long history of slow heart rate and its increase with exercise suggest a congenital mechanism for the conducting tissue defect (Wood, 1960). Furthermore, the electrocardiographic finding of partial right bundle branch block in one other member of this patient's family suggests a familial disorder, similar to the family report of Littler (1970).

\section{Acknowledgment}

We would like to thank Dr P. S. Monro, Neurologist, St George's Hospital, London, for her neurological advice, Dr R. V. Gibson for permission to report patients under his care, and Miss N. Sewell for secretarial help.

\section{References}

Bartle, S.H., Sanmarco, M.E. \& Dammann, J.F. Jr (1965) Ejected fraction: an index of myocardial function. American Journal of Cardiology, 15, 125.

Chatterjee, K., Harris, A., Patrick, J., Alpern, H.L .\& DAvies, M. (1970) The electrocardiogram in chronic heart block. American Heart Journal, 80, 47.

Chatterjee, K., Sacorr, M., Sutton, G.C. \& Miller, G.A.H. (1971) Assessment of left ventricular function by single plane cine-angiographic volume analysis. British Heart Journal. (To be published.)

Davies, M. \& Harris, A. (1969) Pathological basis of primary heart block. British Heart Journal, 31, 219.

Dodge, H.T. \& BAXLEY, W.A. (1969) Left ventricular volume and mass and their significance in heart disease. American Journal of Cardiology, 23, 528.

Harris, A., Davies, M., Redwood, D., Leatham, A. \& SidDons, H. (1969) Aetiology of chronic heart block. A clinico-pathological correlation in 65 patients. British Heart Journal, 31, 206.

Lascells, R.G., BaKer, I.A. \& Thomas, P.K. (1970) Hereditary polyneuropathy of Roussy-Levy type with associated cardiomyopathy. Guy's Hospital Reports, 119, 253.

LitTleR, W.A. (1970) Heart block and peroneal muscular atrophy. Quarterly Journal of Medicine, 39, 431.

Miller, G.A.H., Kirklin, J.W. \& SWAN, H.J.C. (1965) Myocardial function and left ventricular volumes in acquired valvular insufficiency. Circulation, 31, 374.

Sones, F.M. Jr \& ShIREY, E.K. (1962). Cine-coronary arteriography. Modern Concepts of Cardiovascular Disease, 31, 735.

Wood, P. (1960) Diseases of the Heart and Circulation, 2nd edn, p. 324. Eyre \& Spottiswoode, London.

Zоoв, M. \& SмITH, K.S. (1963) The aetiology of complete heart block. British Medical Journal, 2, 1149. 